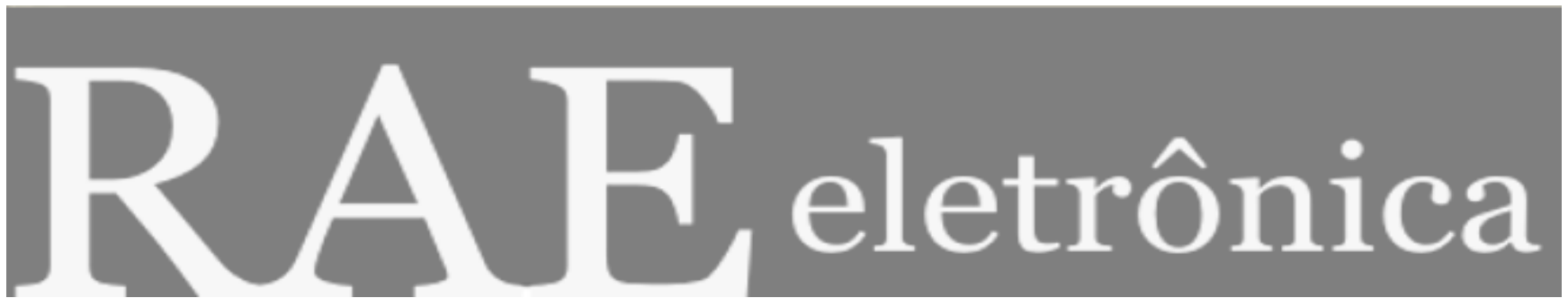

\title{
O PROCESSO DE CRIAÇÃO DE EMPRESAS POR MULHERES
}

Por:

Hilka Vier Machado

Louise St-Cyr

Anne Mione

Marcia Cristina Moita Alves

RAE-eletrônica, v. 2, n. 2, jul-dez/2003.

http://www.rae.com.br/eletronica/index.cfm?FuseAction=Artigo\&ID=1495\&Secao=ORGANIZA\&Volume=2\&Numero=2 $\& A n o=2003$

CCopyright, 2002, RAE-eletrônica. Todos os direitos, inclusive de tradução, são reservados. É permitido citar parte de artigos sem autorização prévia desde que seja identificada a fonte. A reprodução total de artigos é proibida. Os artigos só devem ser usados para uso pessoal e nãocomercial. Em caso de dúvidas, consulte a redação: redacao@rae.com.br.

A RAE-eletrônica é a revista on-line da FGV-EAESP, totalmente aberta e criada com o objetivo de agilizar a veiculação de trabalhos inéditos. Lançada em janeiro de 2002, com perfil acadêmico, é dedicada a professores, pesquisadores e estudantes. Para mais informações consulte o site www.rae.com.br/eletronica.

RAE-eletrônica

ISSN 1676-5648

C2002 Editora: Fundação Getulio Vargas - Escola de Administração de Empresas de São Paulo.
F U N D A Ç Ã 0 GETULIO VARGAS

Escola de Administração de Empresas de São Paulo 


\title{
O PROCESSO DE CRIAÇÃO DE EMPRESAS POR MULHERES
}

\section{Hilka Vier Machado}

Doutora em Engenharia de Produção. Professora da Universidade Estadual de Maringá/PR

E-mail: hilkavier@yahoo.com

Endereço: Rua Saint Hilaire, 2055 - Maringá, PR, 87015-161

Interesses de Pesquisa: mulher empreendedora, comportamento empreendedor, empreendedorismo

\section{Louise St-Cyr}

Doutora em Administração. Professora da École dês Hautes Études Commerciales da Universidade de Montreal

E-mail: Louise.St-Cyr@hec.ca

\author{
Anne Mione \\ Professora da Universidade de Montpelier I \\ E-mail: Gmione@club-internet.fr
}

\section{Marcia Cristina Moita Alves}

Mestranda em Administração UEM

E-mail: mcmoita@yahoo.com.br

\section{RESUMO}

Existe, atualmente, um número significativo de pesquisas sobre o empreendedorismo feminino. No conjunto, esses estudos exploram aspectos ligados ao perfil geral e gerencial das mulheres. A análise da criação de empresas por mulheres é abordada nessas pesquisas, porém de maneira superficial, pois o enfoque principal, em geral, recai sobre o perfil delas ou de suas empresas. Quando se procura entender a criação de empresas e suas implicações, envolvendo os motivos e outros fatores que contribuíram para a decisão de iniciar a empresa, tais como a forma e obtenção de recursos, não há muitas informações disponíveis. Considerando o impacto deste processo no rumo da organização, o propósito deste estudo é o de investigar o processo de criação de empresas por mulheres, em diferentes localidades. Trata-se de uma pesquisa exploratória, realizada com mulheres empreendedoras no Brasil, Canadá e França. Em cada localidade, foram selecionadas 30 mulheres que iniciaram suas empresas, num total de 90 empreendedoras. Nos resultados, discute-se o processo de criação de empresas, a partir das razões para iniciar os negócios, os fatores antecedentes à empresa e, finalmente, sobre as formas de criação, ou seja, as origens do capital inicial e constituição jurídica. A razão predominante para criar a empresa foi a realização pessoal, seguida da visão de oportunidade de mercado e insatisfação no emprego. Predominou um tempo prévio de experiência profissional de 9 anos, em média, e a existência de pais como modelos de empreendedores para $41 \%$ dos casos. A sociedade foi a forma predominante 
e a origem do capital inicial foi proveniente de economias pessoais, com exceção das empresas da França que fizeram parte do estudo.

\begin{abstract}
Currently, there is a significant number of research works about female entrepreneurship. On the whole, these studies explore aspects concerning the women's general and managerial profile. The business creation analysis is superficially mentioned in these works, since the main focus, in general, is either the women's or their business profile. When one attempts to understand the business creation and its implications, involving reasons and other factors that contributed for the decision of starting the business, such as the form and resources obtainment, there is not much information available. Considering the impact of this process on the course of the enterprise, the purpose of this study is to investigate the process of business creation by women, in different places. This is an exploratory research, carried out with women entrepreneurs in Brazil, Canada and France. In each country were selected 30 women who started their business, in a total of 90 women entrepreneurs. In the results the creation process of enterprises is discussed, from the reasons for staring the enterprises, the factors that preceded them and, finally, the forms of creation, that is, the origins of initial capital and juridical organization. The main reason to start an enterprise was personal fulfillment, followed by the market opportunity and job dissatisfaction. A previous professional experience time of 9 years, on average, was predominant, as it was the existence of parents who were entrepreneur models in $41 \%$ of the cases. Partnership was the prevalent organizational form and the initial capital came from personal savings, except for the enterprises studied in France.
\end{abstract}

\title{
PALAVRAS-CHAVE
}

empreendedorismo, criação de empresas, mulher empreendedora, abertura de empresas, gênero.

\section{KEY-WORDS}

entrepreneurship, business venture, women entrepreneur, starting business, gender. 


\section{INTRODUÇÃO}

As mulheres empreendedoras têm desempenhado, atualmente, um papel sócioeconômico importante. Elas fazem parte de um contingente que constitui a maior parte da força de trabalho de vários continentes. Na América do Norte, por exemplo, a percentagem de mulheres economicamente ativas é de 77\%, 49\% na América Latina e Caribe e 77\% na Europa (OIT, 1997).

A inserção feminina no mercado de trabalho e, conseqüentemente, o incremento do número de empreendedoras nas duas últimas décadas motivaram o interesse de pesquisas sobre o exercício do papel empreendedor por mulheres (OECD, 2000). Turner (apud ALLEN \& TRUMAN, 1993) ressalta que, no ano de 1993, na Alemanha e na Dinamarca, para cada 3 empresas criadas, uma era iniciada por mulher, variando uma em cada quatro na França e uma em cada cinco empresas na Grécia, Espanha, Itália, Irlanda e Reino Unido. Também em outros países o empreendedorismo feminino tem aumentado e o resultado é que as mulheres estão iniciando empresas a uma taxa 1,5 vez maior que os homens (OECD, 1998).

Diante dessa situação, no primeiro seminário sobre mulheres empreendedoras, promovido pela OECD, em 1998, foi discutida a importância das mulheres à frente de pequenas empresas. Elas representam metade da população mundial e é crescente o número de empresas que têm criado. Assim, na posição de pequenas e médias empresárias, contribuem como uma fonte importante de empregos, inovação e desenvolvimento econômico. No referido evento, foram destacados três pontos que configuram a importância delas no papel empreendedor: a) econômico: gerando ocupações para elas e para outras pessoas; b) social: possibilitando o equilíbrio trabalho e família; e c) político: aumentando a sua autonomia.

Estudos têm demonstrado que as mulheres abrem empresas por diferentes motivos, tais como: desejo de realização e independência, percepção de oportunidade de mercado, dificuldades em ascender na carreira profissional em outras empresas, necessidade de sobrevivência e como uma maneira de conciliar trabalho e família (CROMIE, 1988; GIMENEZ et al, 1998; HISRICH, 1989; MOORE \& BUTTNER, 1997; STILL \& TIMMS, 1998; VOKINS in ALLEN \& TRUMAN, 1993). Além dessas razões, outros fatores estão ligados à decisão de iniciar um empreendimento, independentemente do gênero, tal como a existência de modelos empreendedores na família.

Apesar da relevância do processo de criação de empresas, pois este pode influenciar a trajetória das empresas criadas, os estudos que abordam a criação de empresas por mulheres estão centrados nos motivos por que elas se tornam empreendedoras (ALVAREZ \& MEYER, 1998; MARLOW, 1997; MALLON \& COHEN, 2001), não focando o processo na íntegra. Uma visão mais abrangente da criação das empresas poderia fornecer um número maior de elementos, que permitiria melhor compreensão da evolução dessas empresas.

Sendo assim, o objetivo deste estudo é investigar o processo de criação de empresas por mulheres, a fim de conhecer e comparar a abertura dessas empresas em diferentes localidades. De modo específico, pretende-se, também, ressaltar distintas experiências de empreender por mulheres, propiciando um referencial de empreender para outros indivíduos, pois a construção de arquétipos sólidos e positivos é importante para uma participação dinâmica das mulheres na mundialização e os modelos de empreendedoras existentes têm refletido elevada credibilidade (OECD, 2000). 
Inicialmente, apresenta-se uma revisão sobre a criação de empresas por mulheres, destacando resultados encontrados em outros estudos. Nesse tópico, foram abordadas as razões para mulheres criarem empresas, os fatores antecedentes, a forma e a origem dos recursos. Após a descrição da metodologia do estudo, os dados foram apresentados e discutidos em conformidade com a mesma estrutura apresentada no quadro conceitual.

\section{O PROCESSO DE CRIAÇÃO DE EMPRESAS POR MULHERES}

A abertura de empresas por mulheres tem sido objeto de políticas públicas em diversos países, tais como: Grécia, Coréia, Espanha, Austrália, dentre outros (LOULOUDI, 2000; OECD, 2000). Mesmo em países em que não existem políticas explícitas de incentivo ao empreendedorismo feminino, a abertura de empresas por mulheres está aumentando. Em algumas localidades, o número de micro e pequenas empresas, iniciadas e dirigidas por mulheres, ocupa proporções quase equivalentes ou superiores aos homens, como, por exemplo, na Finlândia, onde as mulheres possuem a maioria dos hotéis, restaurantes e dos subsetores ligados à area social e aos serviços de saúde (KYRÖ, 2002).

A análise da criação de empresas por mulheres é considerada estratégica para compreender o desenvolvimento dessas organizações (CARTER, 2001; MARLOW, 1997). Embora aparentemente homens e mulheres possuam os mesmos motivos para iniciar seus próprios negócios, tais como: desejo de autonomia e realização, no caso das mulheres há evidências, apontadas em estudos anteriores (GIMENEZ et al, 1998; HISRICH, 1989; STILL \& TIMMS, 1998; VOKINS in ALLEN \& TRUMAN, 1993), que existem motivos de outra natureza, tais como o desejo de conciliar trabalho e família e a insatisfação com a carreira anterior. Nesses casos, esses motivos podem ter maior impacto na decisão de abrir a empresa do que, por exemplo, o desejo de obter ganhos financeiros mais elevados, presente em homens que criam suas empresas (CROMIE, 1987 apud MARLOW, 1997). Desta forma, as estratégias de crescimento da empresa provavelmente serão diferenciadas e estarão ligadas aos motivos da sua criação. Nessas circunstâncias, todo desenvolvimento da organização está atrelado à lógica da criação da empresa. Apesar dessa relevância, a maioria dos estudos realizados com empreendedoras aborda essa questão de maneira superficial.

Outro fator que pode indiretamente exercer influência na decisão de abrir uma empresa é a existência de modelos de referências empreendedores (MOORE \& BUTTNER, 1997), os quais constituem o resultado de um processo de identificação, contribuindo para a construção de um aprendizado empreendedor. No caso específico de empreendedoras, esse aspecto tem sido pouco explorado. O que Still \& Timms (2000) constataram em seus estudos com empreendedoras australianas é que elas tinham dificuldade em encontrar modelos de identificação femininos.

Considerando a abrangência do processo de criação de empresas, bem como a necessidade de discutí-lo em maior profundidade, abordar-se-ão, a seguir, as razões para empreender, os fatores antecedentes ao processo de criação da empresa, bem como as formas e a origem de recursos.

\section{Razões para empreender}

Como razões que motivaram a criação de negócios por mulheres, estudos anteriores mencionaram o desejo de realização e a identificação de oportunidades de negócios (BENNETT \& DANN, 2000; GIMENEZ et al, 1998; OECD, 1998; SEBRAE, 2000; VOKINS apud ALLEN \& TRUMAN, 1993).

Existem outros fatores, tais como a trajetória profissional anterior, que são importantes para uma análise mais abrangente desse processo e que poderiam, por exemplo, contribuir para esclarecer a tendência de que empresas iniciadas e dirigidas por mulheres sejam pequenas. 
Algumas taxonomias desenvolvidas a partir de razões para criação de empreendimentos por mulheres podem esclarecer um pouco mais essa questão. A primeira delas é a de Pastel (apud DAS, 1999), que apresenta: a) as empreendedoras por acaso. Elas iniciam os seus negócios a partir de algum hobby que praticavam e, deste modo, não têm objetivos ou planos claros; b) empreendedoras forçadas a iniciar os negócios por alguma circunstância, tal como a morte do marido ou separação e; c) empreendedoras criadoras: as que criaram as empresas a partir da própria motivação e coragem. Essa classificação é bastante ampla, contudo há aspectos que ela não esclarece, como, por exemplo, quais os elementos que contribuem para motivar e encorajá-las a abrirem as empresas. Outra taxonomia é apresentada pela OECD (2000) e distingue: a) as empreendedoras que não têm outra profissão e o empreendedorismo é a única alternativa. Nesses casos, as suas empresas são, geralmente, individuais e pequenas, pois elas têm pouca experiência nos negócios; b) aquelas que se originam no meio familiar, engajando-se nos negócios familiares; e c) as que criam empresas como estratégias de conquista por razões positivas, tais como independência e autonomia. Nesses casos, há um grande potencial para o desenvolvimento das empresas.

De um modo geral, essas tipologias apontam duas formas distintas de motivações: a primeira delas é circunstancial, enquanto que a segunda é determinada pela vontade pessoal das empreendedoras. Entre aquelas que pertencem ao segundo grupo, ou seja, as que decidem começar a própria empresa, estudos demonstram que alguns motivos são responsáveis por essa decisão, tais como: a dificuldade de ascensão na carreira anterior (BENNETT \& DANN, 2000; HISRICH, 1989; MOORE \& BUTTNER, 1997; OECD, 1998), a necessidade de autonomia profissional e a frustração no trabalho anterior (BENNETT \& DANN, 2000; OECD, 1998). De fato, a ascensão profissional de mulheres em empresas parece difícil. Nesse sentido, Mallon e Cohen (2001) referem-se à propensão existente entre as mulheres que ocupam posições intermediárias nas organizações em abandonar as empresas, a fim de criar a sua própria empresa.

Outra razão para mulheres abrirem empresas é a necessidade de um horário de trabalho flexível. Deste modo, ao criar a própria empresa, elas têm como expectativa melhor conciliar trabalho e família (DAVIES-NETZLEY, 2000; GRENHAUS \& PARASURAMAN, 1999; MALLON \& COHEN, 2001; OECD, 1998; STILL \& TIMMS, 1998, 2000). Esse fator ocorre principalmente nos casos de empreendedoras que possuem filhos pequenos, apesar dos resultados encontrados por Cromie (1988), que identificou grupos de empreendedoras que interromperam suas carreiras em empregos anteriores por causa do nascimento dos filhos e retornaram ao mercado de trabalho como empreendedoras após o crescimento deles.

Outra justificativa apontada por mulheres para criarem empresas (MOORE \& BUTTNER, 1997; VOKINS apud ALLEN \& TRUMAN, 1993) refere-se à insatisfação com o modo pelo qual os homens gerenciam os negócios, acreditando que podem fazê-lo melhor e de forma mais consistente com os seus valores. Salienta-se, ainda, o desejo de aumentar a auto-estima (COLLERETTE \& AUBRY, 1990), mencionado por empreendedoras canadenses e a preocupação com o futuro dos filhos e a necessidade de complementar a renda (principalmente para aquelas que tinham filhos adolescentes ou adultos), citados por empreendedoras que abriram empresas após aposentadas (MACHADO, 1999).

Observa-se que o desejo de aumentar a renda raramente é apontado como motivo por empreendedoras, com exceção de um estudo, realizado junto a 600 norte-americanas (OECD, 1998), no qual este fator foi encontrado em 11\% da amostra. De acordo com Cromie (apud MARLOW, 1997), este é um dos aspectos que distingue a criação de empresas entre homens e mulheres. 
Analisando as razões arroladas pelos estudos anteriores mencionados, o que se pode deduzir é que essas nem sempre são positivas, mas parece que resultam de dificuldades ou incapacidade de conciliar trabalho e família. Todavia, isso não significa necessariamente que o empreendedorismo era a única alternativa profissional para elas. Quando se trata da criação de empresas por mulheres, não só razões econômicas têm sido apontadas, mas também as sociais e psicológicas.

Tendo em vista esse panorama, é importante conhecer as experiências e os relacionamentos anteriores à abertura das empresas, a fim de compreender como esses fatores puderam contribuir para fortalecer a decisão de abrir uma empresa, ainda que para superar outras barreiras.

\section{Fatores antecedentes ao processo de criação das empresas}

Um dos fatores comuns na análise de histórias de vida de empreendedores é a existência de modelos empreendedores na família, principalmente entre os pais ou pessoas mais próximas. Este é um dos determinantes do papel empreendedor, pois no processo de identificação desenvolvido com essas pessoas há um aprendizado cognitivo, afetivamente construído, que resulta na assimilação e na reprodução do modelo e, neste caso, o modelo empreendedor. Partindo dessa premissa, alguns estudos demonstraram uma possível relação entre empreendedoras que tiveram pais ou parentes empreendedores e a opção pelo empreendedorismo (BELCOURT, 1990; GOSSELIN \& GRISÉ, 1990). Esses estudos, porém, não mencionam se a influência também ocorreu para o ramo ou setor de atividade no qual os pais ou modelos atuavam.

Além dos modelos, outro aspecto antecedente importante é a experiência anterior. Esta variável interfere no estabelecimento e na viabilidade de empresas (CARTER, 2001). Hamilton (2002), em um estudo comparativo entre homens e mulheres empreendedoras, encontrou a existência de experiência anterior em ambos os grupos; entretanto, a dos homens era maior. Essa situação não corresponde à encontrada anteriormente por Hisrich (apud CARTER, 2001), na qual as mulheres tinham falta de conhecimento e de treinamento em habilidades gerenciais. Já em um estudo realizado com 600 empreendedoras, nos Estados Unidos (OECD, 1998), foi encontrado o seguinte perfil relativo à experiência anterior: a) 58\% trabalharam no setor privado por mais de 5 anos antes de começarem a empresa; b) $13 \%$ trabalhavam no setor público; c) $41 \%$ trabalhavam no mesmo ramo que estavam atuando.

Outro aspecto importante a ser ressaltado, ainda naquele estudo, é que, do total das entrevistadas, 55\% iniciaram seus negócios como um processo gradual e muitas delas se desligaram da empresa que trabalhavam somente depois que a empresa que abriram estava dando resultados. Essa maneira de estabelecer os negócios lentamente foi também encontrada por Gosselin e Grisé (1990) e Carter (2001). Para esta, o processo de incubação das empresas é maior para as empresas criadas por mulheres do que as criadas por homens. A experiência anterior foi também constatada por Still (in BENNETT \& DANN, 2000), entre mulheres australianas, variando entre 10 e 15 anos antes de iniciar sua própria empresa.

Esses resultados são insuficientes para melhor compreensão da experiência anterior e de seus reflexos no processo de criação das empresas. Assim, embora essa experiência possa atuar como um período de incubação para a criação do próprio negócio, não se sabe se ela ocorre ou não na mesma área de atuação em que as mulheres iniciam as empresas.

Para abranger a discussão do processo de criação das empresas, verificou-se, também, como essas empresas são criadas, ou seja, a forma e a origem dos recursos. 


\section{Forma e origem de recursos}

A forma para abertura da empresa está diretamente relacionada com a participação da empreendedora no capital da empresa.

Poucos estudos exploraram essa questão. Mukhtar (1998) constatou, entre empreendedoras no Reino Unido, o predomínio da propriedade individual. Já entre australianas foi encontrada uma situação na qual elas detêm $50 \%$ da participação do capital, dividindo a outra metade com pessoas da própria família (SOUTAR \& STILL, 2000). Do mesmo modo, em um estudo realizado com empreendedoras canadenses (COLLERETTE \& AUBRY, 1990), 80\% têm sociedade com outra pessoa na empresa e, em 72\% dos casos, essa pessoa é o marido. Entre as que tinham sociedade com o marido, a metade tinha igual participação e a outra metade tinha participação minoritária. Outro dado interessante é que $14 \%$ estavam envolvidas como proprietárias de mais do que uma empresa, geralmente em duas empresas e em sociedade com outra pessoa. A principal razão para constituir sociedades, apontada por elas, é que assim facilitava o financiamento dos negócios, em oposição à motivação encontrada 10 anos atrás pela maioria das mulheres que buscavam sócios porque não acreditavam na sua habilidade gerencial.

É possível que haja uma tendência por parte de mulheres em iniciar empresas na forma de sociedade, não obstante, essa pode ser também uma inclinação para as pequenas empresas, em geral, e não somente para as que são criadas por mulheres.

Apesar de estudos anteriores evidenciarem uma tendência para a forma das empresas em sociedade, não são relacionados possíveis fatores que explicam esse comportamento.

No que tange à origem de recursos para abertura das empresas, estudos anteriores enfatizam que as economias pessoais têm sido predominante. Assim, em um estudo realizado na Austrália, a maioria das mulheres obteve o dinheiro para iniciar suas empresas em suas economias pessoais, enquanto os homens tenderam a obter capital de recursos externos (STILL \& TIMMS, 1998). O que esses estudos não esclarecem é se há alguma relação entre a utilização de economias pessoais e o fato de mulheres encontrarem dificuldades em obterem empréstimos bancários (OECD, 2000).

Considerando os aspectos relativos à criação de empresas por mulheres, observou-se que a maior ênfase nos estudos é atribuída aos motivos pelos quais as mulheres abrem empresas. No que se refere aos outros aspectos que envolvem o referido processo, pouco tem sido explorado. Nesse sentido, este estudo procurou conhecer possíveis relações de causalidade ligadas ao processo de criação de empresas por mulheres.

\section{METODOLOGIA}

Este é um estudo exploratório, realizado junto a empreendedoras de três localidades, em diferentes países: Brasil, Canadá e França. Utilizou-se o método quantitativo de análise, a fim de investigar a criação de empresas por mulheres em uma amostra diversificada, representando, assim, uma contribuição diferenciada para os estudos sobre essa temática, que geralmente abordam a questão de forma parcial e em uma mesma localidade.

A amostra é não probabilística, constituída por 90 empreendedoras que atuam em três cidades pertencentes a países diferentes: Maringá, no Estado do Paraná, localizado no sul do Brasil; Montréal, 
no Canadá, e Paris, na França. Em cada um dos países que integram o estudo, foram selecionadas 30 empreendedoras, com apoio das associações de mulheres de negócios. Dentre essas, foram escolhidas dez mulheres de cada um dos setores: comércio, indústria e serviços. $O$ critério utilizado para selecionar a mulher empreendedora foi o de considerar como tal aquela que abriu a empresa, que possui pelo menos $50 \%$ do capital e que a gerencia. Estes critérios direcionaram a seleção dos casos, juntamente com os setores de atividade.

A coleta de dados foi realizada com a aplicação de questionários semi-estruturados, constituídos por questões abertas e de múltipla escolha. Inicialmente, alguns dados gerais foram coletados, tais como: dados da empresa (ramo de atividades e ano de criação da empresa) e dados das empreendedoras (idade, estado civil, nível de escolaridade e área de formação). Em seguida, o instrumento de coleta de dados foi estruturado sobre as seguintes variáveis: a) razões para iniciar os negócios, avaliadas pelos seguintes indicadores: realização pessoal, perda de emprego, crise pessoal (ex: separação, divórcio), problemas no trabalho anterior, falta de perspectiva na carreira anterior, percepção de oportunidade de mercado, terceirização, mudança de cidade e outras; b) antecedentes ao processo de criação da empresa, analisados através da ocupação dos pais e da experiência anterior da entrevistada (tempo e tipo de atividade); c) forma e origem dos recursos. Quanto à forma, verificaram-se o tipo e o percentual de participação do sócio, em caso de sociedades. No tocante à origem de recursos, as possibilidades eram: economias pessoais, empréstimos bancários (tipo), empréstimos de familiares, empréstimos de amigos ou outras formas.

O mesmo questionário foi aplicado nas localidades do estudo e os dados foram analisados com suporte estatístico SPSS8, utilizando-se, principalmente, a análise descritiva.

\section{APRESENTAÇÃO E DISCUSSÃO DOS DADOS}

As empresas que foram analisadas atuam em diferentes atividades, distribuídas nos setores selecionados (comércio, indústria e serviços). As atividades, de acordo com o setor, estão detalhadas nos quadros 1,2 e 3 . O quadro 1 ilustra as atividades de serviço.

Para o setor industrial, a diversidade está no quadro 2.

A diversificação do comércio está detalhada no quadro 3.

Com relação à freqüência por atividade, para os três setores analisados, a maior incidência foi para os casos de indústria de confecção, encontrada em 5,6\% das empresas, e para a escola, com a mesma proporção $(5,6 \%)$, apesar de que, no caso das escolas, naturezas diferentes foram encontradas, tais como: escola de artes, de música, infantil e de idiomas.

Sobre a idade das empresas, a média foi de 13,37 anos, com um desvio-padrão de 9,7893. A maioria das empresas foi criada na década de 1990 (46 empresas). Ainda assim, vinte e sete empresas foram criadas entre 1970 e 1980, sendo que a empresa mais antiga tem 60 anos e pertence à amostra das empresas canadenses. Entre as empresas brasileiras, a mais antiga tem 32 anos e entre as francesas, 41 anos de atividade.

A maioria das empreendedoras é casada $(52,22 \%)$ e um breve perfil delas foi traçado, destacando-se os aspectos relacionados a:

a) idade: a maior incidência (37,78\% dos casos) está na faixa entre 41 e 50 anos, seguida de 31 a 40 anos (27,78\%). Na faixa de 51 a 60 anos encontram-se $23,33 \%$ dos casos e $8,89 \%$ das 
entrevistadas têm mais do que 60 anos de idade. O menor percentual está na faixa entre 20 a 30 anos de idade (2,22\%). A distribuição por idade e por país pode ser melhor observada na tabela 1 .

b) nível de escolaridade e área de formação: a escolaridade delas é predominantemente graduação completa $(37,78 \%$ dos casos). Em seguida, estão as com nível secundário (29,9\%) e as com pós-graduação (25,5\%). O nível primário foi encontrado em 5,5\% dos casos. Se somados os níveis de graduação e pós-graduação, o nível de escolaridade encontrado foi elevado $(63,28 \%)$. Foi encontrado um caso de analfabetismo.

c) área de formação: as áreas gerenciais ou afins, tais como Administração, Direito, Contabilidade, Comércio, Economia, Informática, Marketing e Turismo foram encontradas em 31,11\% dos casos. Nos demais casos, as áreas de formação foram as de Biblioteconomia, Psicologia, Biologia, Letras, Medicina, Farmácia e Bioquímica, Engenharia Química, Artes e Design em Moda.

d) estado civil: a maioria das empresárias é casada (52,22\%). O percentual de solteiras $(6,67 \%)$ encontrado é menor do que o de viúvas $(8,89 \%)$. Somente $3,3 \%$ não têm filhos. Entre as que têm filhos, poucos foram os casos em que os estes estão numa faixa etária menor do que 10 anos de idade.

e) participação no orçamento familiar. $42,22 \%$ das mulheres são responsáveis por $100 \%$ do orçamento familiar e $32 \%$ participam com, pelo menos, $50 \%$.

f) A maioria delas $(87,8 \%)$ não tem outra atividade remunerada. Entre os onze casos que têm outra atividade, encontraram-se: consultora, fazendeira, diretora de escola e funcionária pública.

Esses dados relativos ao perfil das empresas, bem como das empresárias, coincidem com outros sobre empreendedoras, principalmente nos seguintes aspectos: elevado nível de escolaridade e estado civil: na maioria dos casos são casadas e têm filhos (CARTER, 1992; DAS, 1999; KYRÖ, 2002; MOORE \& BUTTNER, 1997). Embora Hirisch (apud CARTER, 2001) tenha constatado, entre as empreendedoras que pesquisou, a ausência de habilidades gerenciais, para este estudo $31 \%$ das empreendedoras têm formação em áreas gerenciais ou afins.

O processo de criação das empresas será analisado a seguir, inicialmente pelas razões para abrir a empresa.

\section{Razões para criação das empresas}

Os principais motivos encontrados neste estudo para as empreendedoras criarem suas empresas estão detalhados na tabela 2 .

O principal motivo mencionado foi a realização pessoal (30\%). A percepção de oportunidade de mercado aliada com outros fatores foi o segundo motivo (26,66\%). Para 21,11\% dos casos, os motivos envolviam problemas com trabalho anterior, falta de perspectiva na carreira e perda de emprego. Em $17,78 \%$ dos casos, outros motivos, nos quais elas mencionaram: razões ligadas a questões familiares; perda do marido; para encontrar uma ocupação para a família; porque queria comprar a empresa do pai; porque comprou a empresa onde trabalhava; porque a família tinha empresa em outra cidade e abriu 
uma filial; e como um incentivo por parte de familiares. Desta forma, razões do tipo "voluntárias" foram predominantes.

Quando analisados os dados separadamente, em cada país, a mesma tendência foi encontrada nos casos brasileiros. Nesses casos, o principal motivo também foi a realização pessoal $(26,7 \%)$. Em segundo lugar, esteve a realização pessoal associada com oportunidade de mercado (16,7\%). Perder o emprego ou falta de perspectiva na carreira anterior foi a razão pela qual $6,6 \%$ desses casos iniciaram empresas.

Para os casos de empresas do Canadá, foi encontrada uma variação um pouco diferente. A realização pessoal e a percepção de oportunidade de mercado aparecem isoladamente com os mesmos percentuais $(13,3 \%)$. Problemas no trabalho anterior, falta de perspectiva na carreira anterior e percepção de oportunidade de mercado representaram outros 13,2\% adicionais. No conjunto dos casos canadenses, 33,3\% mencionaram "outros" motivos, representados por razões pessoais ou ligadas à família. Já a falta de perspectiva na carreira anterior e o fato de perder o emprego corresponderam a $10 \%$ das razões.

Nos casos da França, a realização pessoal foi a mais representativa: 45,2\%. Para 6,5\% dos casos, a percepção de oportunidade de mercado foi a razão para iniciar a empresa. Esse percentual está bem próximo de porque perdeu o emprego $(6,4 \%)$.

É importante ressaltar que, na amostra geral, foi encontrado um grupo representado pelas que atuaram durante 20 anos ou mais na ocupação anterior, que corresponde a 8,88\%, cujos motivos apresentados para abrir suas empresas têm relação com a ausência de perspectiva na carreira anterior, a perda de emprego ou o conflito na sociedade anterior. Deste grupo, apenas 3,3\% abriu a empresa por realização pessoal.

De modo geral, a realização pessoal foi o principal motivo para abertura das empresas, seguida de percepção da oportunidade de mercado. A falta de perspectiva na carreira anterior ou o desemprego representou aproximadamente $21 \%$ dos casos.

Convém salientar que essas empresas estudadas foram criadas há mais de 5 anos, sendo que a maioria delas tem mais de 10 anos de atividade. Pode-se supor que, para as empresas criadas em anos mais recentes, a falta de emprego ou de perspectiva na carreira possa ser mais representativa.

\section{Fatores antecedentes à criação das empresas}

Primeiramente, analisou-se a ocupação dos pais das empreendedoras, a fim de verificar a existência de modelos de referência empreendedora. Sob esse aspecto, constatou-se que, embora não representando a maioria dos casos, um percentual significativo delas teve o pai como modelo de empreendedor $(45,6 \%)$. O percentual empreendedor foi menor para as mães: $24,4 \%$, porém, considerando a dificuldade em encontrar modelos de referência empreendedora femininos (STILL \& TIMMS, 1998), esse resultado é significativo.

No que concerne à ocupação dos pais empreendedores, predominou o empreendedorismo rural (agricultor, agropecuarista, dono de "erablière" - planta típica do Canadá - , fazendeiro, pecuarista, sitiante), correspondendo a $24,3 \%$ dos casos. Os comerciantes representaram $6,7 \%$ dos casos e os profissionais liberais 7,7\%. Não foi encontrada relação entre a atividade realizada pelos pais e a desenvolvida nas empresas onde as empreendedoras atuam. 
Sobre a ocupação das mães, o predomínio foi para as atividades do lar (55,6\%). Entre aquelas que exerceram atividade empreendedora, encontraram-se costureiras, donas de atelier de costura, de confecção, empresárias rurais e comerciantes. Parece haver uma relação também com a natureza da atividade, quando se trata de modelos maternos de empreendedoras.

Outro fator antecedente observado foi a atividade exercida anteriormente pelas empreendedoras, bem como o tempo em que atuaram nela. Aproximadamente 53,57\% delas eram empregadas em outras empresas, exercendo atividades tais como: secretária $(3,3 \%)$, vendedora $(3,3 \%)$, encarregada de serviços $(2,2 \%)$, compradora $(2,2 \%)$, caixa, bibliotecária, técnica de contabilidade, operadora de crédito, dentre outras. Outra ocupação exercida por elas foi a de professora para 26,6\% dos casos. Em $3,3 \%$ dos casos, tiveram experiência em outra empresa. Para 3,3\%, a atividade anterior era do lar e $4,4 \%$ eram estudantes. Desta forma, se considerarmos conjuntamente as empregadas em outras empresas e as professoras, $80,17 \%$ delas trabalhavam em outros empregos. Entre aquelas que tiveram experiência anterior, a maioria ocupou posições intermediárias, sem experiência gerencial, com exceção de dois casos que tiveram experiência como diretoras de empresas.

Analisando-se a relação entre a atividade anterior e o ramo escolhido para iniciar os negócios, encontrou-se uma semelhança em aproximadamente $30 \%$ dos casos. Por exemplo: as que eram professoras - de música, de idiomas, de artes plásticas - abriram escolas na mesma área que atuavam, ou ainda, costureiras que iniciaram indústria de confecções; biólogas que foram atuar com horticultura ou com pesquisa e desenvolvimento farmacêutico.

É importante mencionar que, em uma pesquisa desenvolvida junto a empreendedoras norte-americanas (OECD, 1998), 58\% das empreendedoras tinham experiência anterior no setor privado por mais de 5 anos antes de iniciar a empresa. No presente estudo, constatou-se que 53,57\% das entrevistadas trabalhavam no setor privado e $60 \%$ tiveram experiência prévia igual ou superior a 5 anos. Enquanto que no estudo desenvolvido com norte-americanas $41 \%$ trabalhavam anteriormente no mesmo ramo que foram atuar como empreendedoras, neste estudo, esse percentual foi de aproximadamente $30 \%$ dos casos.

Observou-se, ainda, que, apesar da maioria das entrevistadas (53,57\%) ser empregada em outras empresas anteriormente, a falta de perspectiva na carreira não foi o principal motivo apontado por elas para a abertura das empresas. Todavia, se se considerar que a realização pessoal foi o principal motivo, pode-se supor que muitas das que mencionaram esse motivo não se realizaram no emprego anterior e deixaram a empresa na qual trabalhavam para encontrar realização na própria empresa. É possível, ainda, supor que o nível de autonomia e perspectiva na ocupação anterior não tenha permitido atingir uma realização pessoal, contribuindo para a decisão de iniciar a própria empresa.

No que diz respeito ao tempo de experiência anterior, verificou-se que aproximadamente $60 \%$ das empreendedoras permaneceu mais do que 5 anos na atividade anterior e 4,4\% dos casos não tiveram experiência anterior. Melhor detalhamento da experiência anterior é apresentado na tabela 3.

O tempo médio de experiência anterior foi de 8,8 anos para os casos canadenses; 8,44 para os brasileiros e 10,13 para os da França.

É importante ressaltar que para $17,26 \%$ dos casos a experiência anterior foi superior a 16 anos de atividade. O maior tempo correspondeu a 28 anos. Se analisado separadamente entre os países, o percentual daquelas que permaneceram mais do que 20 anos na atividade anterior, este corresponde a $12,9 \%$ para a França; 6,6\% para o Canadá e 6,7\% para o Brasil. 
A maioria dos casos que tinham mais do que 16 anos de experiência iniciaram as empresas porque perderam o emprego ou porque tiveram problemas no emprego anterior.

De modo sucinto, sobre os fatores antecedentes ao processo de criação das empresas, observou-se que a maioria das empreendedoras teve pais e mães empreendedores. A experiência anterior foi o fator antecedente mais relacionado com o ramo de atividade escolhido. Também a área de formação escolar teve correspondência com a atividade da empresa.

Para completar a abordagem do processo de criação das empresas, apresentam-se os resultados da forma e origem dos recursos.

\section{Forma e origem de recursos}

A forma predominante para o capital inicial das empresas criadas foi através de economias pessoais $(35,6 \%)$. Em conjunto com outras formas, tais como empréstimo de familiares, empréstimo de amigos e outras formas, esse percentual representou $40 \%$.

Além destas modalidades, o empréstimo bancário, do tipo hipoteca, foi constatado em $10 \%$ dos casos e $15,5 \%$ quando associado com outras formas, tais como empréstimo bancário, empréstimo de familiares e Prime (esta última uma modalidade de empréstimo fornecida pelo governo francês). No mesmo percentual, foram encontrados outros empréstimos bancários. Quando associado com outras formas de empréstimos, de amigos, familiares e economias pessoais, o percentual de participação foi de $18,8 \%$. Além dessas formas de origem do capital inicial, outros dois casos encontrados referem-se à venda de um imóvel e outro do penhor de jóias.

Consoante o estudo realizado, entre as empreendedoras brasileiras e canadenses, as economias pessoais e os empréstimos familiares, em conjunto, representam a maioria das origens de capital inicial: $66,7 \%$ e 56,7\%, respectivamente. Para a França, essas modalidades representam 25,9\% das origens de capital, sendo $58 \%$ por meio de empréstimos bancários, do tipo hipoteca ou Prime. Para os casos brasileiros, os empréstimos bancários representaram $6,7 \%$ e $23,2 \%$ para os canadenses.

No grupo das empresárias que tiveram experiência anterior em outra atividade por mais de 20 anos, $(8,8 \%)$ as origens de capital foram provenientes de: a) economias pessoais; b) empréstimos bancários; c) empréstimos de amigos e familiares; e d) programa de ajuda a desempregados, num pequeno percentual.

Finalmente, quanto à forma jurídica, predominou a sociedade com outras pessoas (67\% dos casos). Dos 60 casos de sociedades, 19 são com o marido, 23 com outras pessoas da família, tais como: cunhado, irmão, irmã ou filhos e 18 com outras pessoas. Se considerados os casos de cada país, isoladamente, a forma em sociedade também foi predominante. A exceção encontrada está entre as empreendedoras com mais de 20 anos de experiência anterior, que optam por abrirem firmas individuais ou com $80 \%$ de participação no capital da empresa, indicando uma possível associação entre tempo prévio de experiência e forma jurídica da empresa.

O processo de criação de empresas por mulheres, analisado neste estudo, pode ser resumidamente detalhado, por meio de quatro questões e suas respectivas respostas:

a) Por que as mulheres criaram suas empresas? Principalmente por realização pessoal (30\%). Em seguida, a percepção da oportunidade de mercado (mesmo que em conjunto com outros fatores) e problemas relacionados com a ocupação anterior, com a falta de perspectiva na carreira ou perda de 
emprego. Esse último aspecto teve uma relação com as de maior idade e maior experiência profissional.

b) Quais fatores atuaram como determinantes na decisão de abrir a empresa? Neste estudo, mais do que $80 \%$ eram empregadas antes de abrirem suas empresas. A experiência prévia nesta atividade foi de 9 anos, em média. A falta de perspectivas no trabalho anterior e a visão de oportunidade de mercado exerceram influência na criação de suas empresas. É possível também que o fato de terem pais e mães empreendedoras (aproximadamente $70 \%$ quando considerados em conjunto) tenha interferido na decisão de empreender.

c) Como abriram suas empresas? Para as brasileiras e as canadenses que fizeram parte do estudo, a maioria abriu empresas com economias pessoais. As francesas o fizeram com empréstimo bancário. A maioria buscou sociedade com familiares, amigos ou maridos. A maioria $(87,8 \%)$ também deixou sua atividade anterior para dedicar-se integralmente à empresa criada.

d) O que determinou a escolha do ramo e do setor de atividades? A oportunidade de mercado, aliada à experiência anterior, similar ao ramo de atuação para $30 \%$ dos casos.

\section{CONSIDERAÇÕES FINAIS:}

Este estudo analisou a opção de mulheres pelo empreendedorismo. Partindo de uma diversidade de setores econômicos, a maioria das empresas estudadas foi criada na década de 90, mas até 60 anos de atividade foram encontrados.

A principal razão foi a realização pessoal. Contudo, quando se constata que a maioria delas trabalhava em outras empresas anteriormente, a realização pessoal pode significar que a atividade anterior não propiciou essa satisfação. Nesse sentido, parece que, sob esse motivo, está implícita a insatisfação com os limites da atividade anterior. A decisão de buscar essa realização numa empresa própria pode ter sido reforçada pelo elevado nível educacional delas. Deste modo, a principal razão é, de fato, o desejo de melhorar as perspectivas de atuação no mercado de trabalho. Isso ocorreu independentemente do tempo de trabalho, pois casos de até 28 anos de experiência prévia foram verificados. A decisão de empreender foi impulsionada pela visão da oportunidade de mercado e pelo conhecimento do setor (30\% dos casos), apesar da pouca experiência gerencial.

As economias pessoais constituíram a principal origem de capital, exceto para as empreendedoras francesas estudadas. Dessa maneira, embora estudos apontem a tendência por parte de mulheres em abrirem empresas com economias pessoais, é provável que outros aspectos, possivelmente ligados a políticas públicas ou conjuntura econômica da localidade, tenham também impacto nessa decisão.

A forma predominante foi a sociedade, principalmente com marido ou pessoas da família. A exceção encontrada foi para as que tinham mais do que 20 anos de experiência, permitindo supor uma associação entre idade, tempo de experiência e forma de criar as empresas.

Desta forma, ao analisar a criação de empresas por mulheres, alguns pontos que não foram abordados em outros estudos puderam ser verificados, tais como:

- Relação entre a experiência anterior e o ramo escolhido;

- Relação entre a natureza de atividade e a atividade exercida por modelos de referência por parte de mães; 
- Possível relação entre o tempo de experiência e a forma de constituir a empresa;

- Uma nova categoria de empreendedoras "forçadas", constituída por mulheres com mais de 20 anos de experiência, que foram demitidas de outros empregos.

Apesar de melhor esclarecer aspectos relativos ao processo de criação de empresas por mulheres, algumas limitações foram encontradas e podem ser observadas em estudos posteriores, tal como a informação sobre o valor do capital inicial. Outros pontos que podem ser explorados em outros estudos referem-se ao detalhamento do projeto da empresa (a adoção de planos de negócios, de pesquisas de mercado), tempo entre a decisão de abrir a empresa e a efetiva abertura, tentativas de obtenção de recursos junto a instituições financeiras, bem como detalhes relativos à implementação da empresa (escolha do local, da equipe).

É importante ressaltar que a generalização dos resultados deste estudo restringe-se aos casos analisados, em razão do tamanho da amostra, que não é representativa das populações estudadas.

\section{Artigo recebido em 30.07.2002. Aprovado em 28.04.2003}

\section{BIBLIOGRAFIA}

ADLER, N. Global Leaders: Women of Influence in Work in Powell, G.N. Handbook of Gender \& Work, London: Sage, 1999.

ALLEN, S \& TRUMAN, C (Editors) Women in business - perspectives on women entrepreneurs. London: Routledge, 1993.

ALVAREZ, S. e MEYER, G.D. Why do women become entrepreneurs? Babson College, http://www.babson.edu/entrep/ter/paper98/text.htm, 1998.

ANNA, A. L.; CHANDLER, G.N, JONSEN, E. and MERO, N.P. Women Business Owners in traditional and non-traditional industries. Journal of Business venturing 15, p. 279-303, 1999.

BELCOURT, M. A Family Portrait of Canada's most successful female entrepreneurs. Journal of Business Ethics 9, p. 435-438, 1990.

BENNETH, R. and DANN S. The changing experience of australian female entrepreneurs. Gender, Work and Organisation, 7(2), p.75-83, 2000.

BOWEN, D. \& HISRICH, R. The female entrepreneur: a career development perspective. Academy of Management Review. Vol 11 (2), p. 393-407, 1986.

CARTER, N. and ALLEM, K. Size determinants of women-owned businesses: choice or barriers to resources? In Special Entrepreneurship and Regional Development Journal, 9(3), p. 211-220, 1997. 
CARTER, S. and ROSA,P. The financing of male and female owned businesses. Entrepreneurship and Regional Development. Vol 10(3), p. 223-241, 1998.

CARTER, S. CANNON. T. Women as entrepreneurs. London: Academic Press, 1992

CARTER, S. Women's business ownership: a review of the academic, popular and internet literature. Glasgow: University of Strathclyde, 2001

COLLERETTE, P; AUBRY, P. Socio-Economic Evolution of Women Business Owners in Quebec. Journal of Business Ethics, 9, p.417-422, 1990.

CROMIE, S. \& HAYES, H.Towards a typology of female entrepreneurs. The Sociological Review, 6(1), p. 87-113, 1988.

DAS, M. Women entrepreneurs from southern India: an exploratory study. The Journal of Entrepreneurship, 8(2), p. 147-163, 1999.

DAVIES-NETZLEY,S. Gendered Capital Entrepreneurial Women in American Society. New York: Garland Publishing, 2000.

DUCHÉNEAUT, B; ORHAN, M. Les femmes entrepreneurs en France. Paris : Sli Arlas, 2000.

GIBSON, C.B. An investigation of gender differences in leadership across four countries. Journal of International Business Studies, London, Second Quarter, vol 26(2), p.255-274, 1995.

GIMENEZ, F; MACHADO, H. e BIAZIN, C. (1998). A mulher empreendedora: um estudo de caso no setor de confecções, In: 1998 Balas Proceedings. Texas, Vol.1, p.311-322, 1998.

GOSSELIN, H. and GRISÉ, J. Are women owner-managers challenging our definitions of Entrepreneurship? Journal of Business Ethics, 9, p. 423-433, 1990.

GRENHAUS, J e PARASURAMAN, S. Research on Work, Family and Gender in Handbook Gender \& Work, London: Sage, 1999.

GROUPE DE TRAVAIL SUR L'ENTREPRENEURIAT FÉMININ. Entreprendre au féminin. Rapport Ministère de l'Industrie du Commerce, de la Science et de la Techonologie de Québec, Montreal, 1997.

GROUPE CONSEIL SUR L'ENTREPRENEURIAT FÉMININ. Les défis des entrepreneures. Gouvernement du Québec, Montréal, 2000.

HAMILTON, L.C. Female Entrepreneurs: Overcoming Problems and Reacting to Challenges. In 2002 ICSB Proceedings. Porto Rico, 2002.

HERNANDEZ, E.M. Le processus entrepreneurial vers un modèle stratégique d'entrepreneuriat. Paris :L'Hartmann, 1999.

HISRICH, R. Entrepreneurship: starting, developing and managing a new enterprise. Boston, 1989. 
HISRICH, R.; BRUSH, C. G.; GOOD, D. e D, GITA. Performance in entrepreneurial ventures: goes gender matter? Frontiers of Entrepreneurship Research. Babson College, 1997.

HOLMQUIST, C. Women's entrepreneurship - complement or alternative? Special Issue Entrepreneurship and Regional Development Journal, 9(3), 1997.

INMAN, K. Women's Resources in Business Start-ups. A study of black and white women entrepreneurs. London: Garland Publishing, 2000.

IZYUMOV, A. and RAZUMNOVA, J Women entrepreneurs in Russia: learning to survive in the market. Journal of Developmental Entrepreneurship, vol 15(1), p.1-19, 2000.

JONES, K. Psychodynamics, gender and reactionary entrepreneurship in metropolitan São Paulo, Brazil. Women in Management Review, 15(4), p. 207-217, 2000.

KYRÖ, P. Reports from the School of business and Economics: Woman Entrepreneurship in the Nordic Countries, vol I e II. Finlandia: University of Jyväskyla, 2002.

LOULOUDI, A. Women's entrepreneurship in the technological sector in Greece in OECD Conference Women Entrepreneurs in SMEs. Paris: OECD, 2000.

MACHADO, H. V. \& GIMENEZ, F.P. Casais Empreendedores: do contrato civil ao contrato administrativo. XIX Encontro Nacional de Engenharia de Produção. Proceedings. Rio de Janeiro, 1999.

MALLON, M. e COHEN, L. Time for a Change? Women's Accounts of the Move from Organizational Careers to Self-Employment. British Journal of Management, 12, p.217-230, 2001.

MARLOW, S. Self-employed women - new opportunities, old challenges? Entrepreneurship \& Regional Development, 9, p. 199-210, 1997.

MOORE, D. e BUTTNER, H. Women's organizational exodus to entrepreneurship: self-reported motivations and correlates with success . Journal of Small Business Management, jan. p. 34-47, 1997.

MOORE, D. P. e BUTTNER, E. H. Women Entrepreneurs. London : Sage Publications, 1997.

MUKHTAR, J. Business characteristics of male and female small and medium enterprises in the UK: implications for gender-based entrepreneurialism and business competence development. British Journal of Management. Vol 9, p. 41-51, 1998.

OECD. Proceedings of Women Entrepreneurs in Small and Medium Enterprises. Paris:OECD, 1998.

OECD . Les femmes entrepreneurs à la tête de PME: pour une participation dynamique à la mondialisation et à l'économie fondée sur le savoir. 29-3- nov. Paris, 2000.

OIT - Organisation Internationale du Travail. Programme des activités sectorielles. La promotion des femmes aux postes de direction. Genève : Bureau International du Travail, 1997. 
SEBRAE. Departamento Nacional do Comércio. II Sondagem SEBRAE. A mulher empresária, pesquisa, vol 9, nov 2000.

SMALL ENTERPRISE DEVELOPMENT. SEBRAE- Support for small enterprise in north Brazil, vol 10(2), p.67-68, 1999.

STILL, L \& TIMMS, W . Women in Small Business: Towards a new paradigm. ICSB Singapore Conference Proceedings. HYPERLINK http://www.icsb.org/pubs/98 http://www.icsb.org/pubs/98 papers/index.html, 1998.

SOUTAR, G. e STILL, L. Reasons for Small to Medium Enterprise Startups: a correspondence analysis. ICSB World Conference Proceedings. Brisbane, jun 2000. 1 CD.

STILL, L. \& TIMMS, W. Women's business: the flexible alternative workstyle for women. Women in Management Review, vol 15(5/6), p.272-283, 2000.

VERSTRAETE, T. Entrepreneuriat- Connaître l'entrepreneur, comprendre ses actes. Paris: L'Hartmattan, 1999.

VERSTRAETE, T. L'Entrepreneuriat un phénomène aux multiples formes d'expression in Histoire d'entreprendre les réalités de l'entrepreneuriat. Paris: Édition EMS-Management \& Societé, 2000. 
Quadro 1: Distribuição das atividades ligadas ao setor de serviços, por localidade do estudo:

\begin{tabular}{|l|l|l|}
\hline Brasil & Canadá & França \\
\hline Escola infantil; & Escola de artes e pesquisa em infografia; & Imobiliária; \\
Escola de música; & Publicidade; & Escritório de seguros; \\
Artesanato; & Jornal comunitário; & Laboratório de análises clínicas; \\
Escola de idiomas; & Divertimento; & Assessoria comercial; \\
Divertimento. & Consultoria em transporte. & Cuidado de cães; \\
& & Escritório de contabilidade; \\
& & Instituto de beleza; \\
& Consultoria em assuntos europeus. \\
\hline
\end{tabular}

Quadro 2: Distribuição das atividades ligadas ao setor da indústria, por localidade do estudo:

\begin{tabular}{|l|l|l|}
\hline Brasil & Canadá & França \\
\hline Material de limpeza; & Ingredientes alimentícios; & Gráfica; \\
Confecção; & Horticultura; & Metalúrgica; \\
Grampos para escritório; & Fabricação de portas e janelas; & Plásticos; \\
$\begin{array}{l}\text { Manipulação de produtos } \\
\text { farmacêuticos; }\end{array}$ & Confecção; & Massas congeladas; \\
Artigos para viagem; & Indústria gráfica; \\
$\begin{array}{l}\text { Confecção de roupas de banho e } \\
\text { esportivas. }\end{array}$ & $\begin{array}{l}\text { Transformação de produtos } \\
\text { agrícolas; }\end{array}$ & Marcenaria. \\
\hline
\end{tabular}


Criação de jogos educativos;

Produção de vinho;

Fabricação de barracas para o exército canadense.

Quadro 3: Distribuição de atividades ligadas ao comércio, por localidade estudada

\begin{tabular}{|l|l|l|}
\hline Brasil & Canadá & França \\
\hline Tecidos; & Roupas; \\
Material de construção; & $\begin{array}{l}\text { Distribuição de produtos } \\
\text { ecológicos; } \\
\text { Móveis e decoração; }\end{array}$ & $\begin{array}{l}\text { Louças; } \\
\text { Programas de inteligência } \\
\text { artificial. } \\
\begin{array}{l}\text { Atacadista e varejista de producis; } \\
\text { para indústria de confecção; } \\
\text { Calçados; }\end{array}\end{array}$ \\
$\begin{array}{l}\text { Material de desenho; } \\
\text { Flores. }\end{array}$ & $\begin{array}{l}\text { Supermercado; } \\
\text { Exportação de vinho; } \\
\text { Madeiras; } \\
\text { Alimentos preparados. }\end{array}$ \\
\end{tabular}

Tabela 1: Distribuição da idade das empreendedoras

\begin{tabular}{|l|l|l|l|l|}
\hline Idade/País & Brasil (\%) & Canadá (\%) & França (\%) & Total (\%) \\
\hline 20 a 30 & - & 3,3 & 3,2 & 2,22 \\
\hline 31 a 40 & 36,6 & 26,7 & 19,4 & 27,78 \\
\hline 41 a 50 & 50,0 & 33,3 & 25,8 & 37,78 \\
\hline 51 a 60 & 6,6 & 23,3 & 38,7 & 23,33 \\
\hline
\end{tabular}




\begin{tabular}{|l|l|l|l|l|}
\hline mais que 60 & 3,3 & 13,3 & 9,7 & 8,89 \\
\hline
\end{tabular}

Tabela 2: Principais razões apontadas pelas empreendedoras para criação das empresas

\begin{tabular}{|c|c|c|}
\hline Razão & $\begin{array}{l}\text { Frequê } \\
\text { ncia }\end{array}$ & Percentual \\
\hline Realização pessoal & 27 & 30 \\
\hline Realização pessoal e porque perdeu o emprego & 1 & 1,11 \\
\hline Realização pessoal, perdeu o emprego e crise pessoal & 1 & 1,11 \\
\hline $\begin{array}{l}\text { Realização pessoal, perdeu o emprego, percepção de oportunidade } \\
\text { de mercado }\end{array}$ & 1 & 1,11 \\
\hline Realização pessoal e problemas no trabalho anterior & 1 & 1,11 \\
\hline $\begin{array}{l}\text { Realização pessoal, problemas no trabalho anterior e falta de } \\
\text { perspectiva na carreira anterior }\end{array}$ & 1 & 1,11 \\
\hline Realização pessoal e falta de perspectiva na carreira anterior & 2 & 2,22 \\
\hline $\begin{array}{l}\text { Realização pessoal, falta de perspectiva na carreira anterior } \mathrm{e} \\
\text { percepção de oportunidade de mercado }\end{array}$ & 1 & 1,11 \\
\hline Realização pessoal e percepção de oportunidade de mercado & 9 & 10 \\
\hline $\begin{array}{l}\text { Realização pessoal, percepção de oportunidade de mercado e } \\
\text { problemas no trabalho anterior }\end{array}$ & 1 & 1,11 \\
\hline Perdeu o emprego & 4 & 4,44 \\
\hline Perdeu o emprego e mudou de cidade & 1 & 1,11 \\
\hline Crise pessoal (separação, divórcio) & 4 & 4,44 \\
\hline $\begin{array}{l}\text { Problemas no trabalho anterior, falta de perspectiva na carreira } \\
\text { anterior e percepção de oportunidade de mercado }\end{array}$ & 1 & 1,11 \\
\hline Falta de perspectiva na carreira anterior & 2 & 2,22 \\
\hline $\begin{array}{l}\text { Falta de perspectiva na carreira anterior, percepção de oportunidade } \\
\text { de mercado e realização pessoal }\end{array}$ & 1 & 1,11 \\
\hline Percepção de oportunidade de mercado & 8 & 8,89 \\
\hline $\begin{array}{l}\text { Percepção de oportunidade de mercado e falta de perspectiva na } \\
\text { carreira anterior }\end{array}$ & 1 & 1,11 \\
\hline
\end{tabular}




\begin{tabular}{|l|l|l|}
\hline Percepção de oportunidade de mercado e mudança de cidade & 1 & 1,11 \\
\hline Percepção de oportunidade de mercado e outras & 1 & 1,11 \\
\hline Mudança de cidade & 3 & 3,33 \\
\hline Outros & 16 & 17,78 \\
\hline Outros e realização pessoal & 1 & 1,11 \\
\hline
\end{tabular}

Tabela 3: Tempo de experiência anterior

\begin{tabular}{|l|l|l|l|l|}
\hline Tempo que permaneceu na atividade anterior & Total & Brasil & Canadá & França \\
\hline não teve experiência & 4,44 & 13,33 & - & - \\
\hline até 5 anos & 35,56 & 19,8 & 43,5 & 32,3 \\
\hline 6 a 15 anos & 42,22 & 43,3 & 33,3 & 48,5 \\
\hline 16 a 20 anos & 8,88 & 10,0 & 13,3 & 3,2 \\
\hline 21 a 28 anos & 8,88 & 6,7 & 6,6 & 12,9 \\
\hline
\end{tabular}

